\title{
ORGAN SPECIFIC CHANGES IN ENERGY METABOLISM DUE TO ANAEROBIOSIS IN THE SEA MUSSEL MYTILUS EDULIS (L.)
}

\author{
W. Zurburg and J. H. Kluytmans \\ Laboratory of Chemical Animal Physiology, State University of Utrecht, 8 Padualaan, \\ 3508 TB Utrecht, The Netherlands
}

(Received 24 January 1980)

\begin{abstract}
Anaerobic energy metabolism was investigated in different organs of Mytilus edulis and the whole animal.

2. Succinate accumulates to high levels in most organs but remains low in the hemolymph.

3. After 16 hours propionate accumulation is observed in all organs. Experimental evidence is not sufficient yet to point out organs that produce more propionate than others.

4. Acetate is a minor end product.

5. Acetate and propionate are found in the hemolymph in amounts equal to those in the organs.

6. Animals incubated in oxygen-free seawater accumulate more end products than animals exposed to air, in the form of volatile fatty acids that are excreted into the incubation water.

7. Alanine and glutamate increase in the posterior adductor muscle. Aspartate decreases in the total animal, posterior adductor muscle and gills, while in the hemolymph decreases in alanine, asparagine, serine, threonine and proline are observed.
\end{abstract}

\section{INTRODUCTION}

Investigations on anaerobic metabolism in molluses result in a picture of increasing complexity and flexibility. The number of end products formed by carbohydrate degradation is still growing. Besides the classical end products like lactate, octopine, succinate and alanine, recently volatile fatty acids and $N$-carboxyethyl-alanine have been detected in bivalved molluscs (Kluytmans et al., 1975; Collicut \& Hochachka, 1977). The nature of the fermentation products can vary per species, but additionally quantitative fluctuations are observed due to factors like time of anoxia, temperature and seasonal cycle. Even within one animal differences in metabolic pathways will exist in the distinctive organs. For Mytilus edulis fluctuations in energy substrates such as glycogen, proteins and lipids have been followed during the annual cycle in several organs (Zurburg et al., 1979). The accumulation of glycolytic end products in different organs of $M$. edulis has been investigated by Kluytmans et al. (1977, 1978). After longer periods of anoxia excretion of volatile fatty acids (acetate and propionate) is observed (Kluytmans et al., 1978), when the mussels are incubated in seawater without oxygen. As transport of end products to the environment can occur, internal transport phenomena can be expected. End products formed in one specific organ could be removed from the place of production into other organs and further converted, e.g. succinate into propionate. Therefore, in this investigation on organ specificity in anaerobic metabolism the hemolymph has been included among the different organs. The role of free amino acids other than alanine seems to be of minor importance in anaerobic metabolism. In the total mussel as well as in some organs as the posterior adductor muscle, an increase in glutamate and a decrease in aspartate levels during anoxia are sometimes observed (Kluytmans et al., 1977; De Zwaan, 1977; Livingstone \& Bayne, 1977). However, seasonal variations in these changes due to anoxia and sometimes no changes at all are found (Kluytmans et al., 1980). Equally the accumulation of alanine varies seasonally. Until now only the accumulation of alanine was investigated in the distinct organs (Kluytmans et al., 1977). In this study the role of other amino acids has been examined in different organs as well as in the hemolymph.

Recently it was demonstrated by Widdows et al (1979) that M. edulis is able to consume some oxygen from the air when exposed, but anaerobic end products still accumulate in the tissues. In our investigation two experimental conditions were compared: exposure to air and incubation in oxygen-free seawater to investigate to what extent the oxygen consumption in air influences formation of anaerobic end products.

\section{MATERIALS AND METHODS}

\section{Animals}

Sea mussels (Mytilus edulis L.) were supplied by the Netherlands Institute for Fisheries Investigations, Department of Shellfish Research (Texel, The Netherlands). The animals were collected in July 1977, transported to Utrecht and kept without food in recirculating seawater at $12 \mathrm{C}$ for 2 weeks. Mussels with a shell length between 5.5 and $6.5 \mathrm{~cm}$ were selected and used for the experiments.

\section{Experimental procedure}

Groups of 30 mussels were incubated in oxygen-free seawater $\left(10\right.$ animals per litre), or exposed to air at $12-13^{\circ} \mathrm{C}$ for periods of $4,16,24$ and $48 \mathrm{hr}$. Three groups of 30 mussels were taken directly out of the aquarium tanks to 
serve as control groups ( $0 \mathrm{hr}$ of anaerobiosis) with intervals of $24 \mathrm{hr}$ to cover the complete period of experimentation (3 days) in order to take into account the possible effect of two more days of starvation.

After each period of incubation or exposure one group of 30 animals was examined as a whole, from another group of 30 animals the following organs were analysed separately: posterior adductor muscle, the combined remaining muscles, gills, mantle, digestive gland and the rest (i.e. the pooled remaining tissues, enclosed seawater and hemolymph). Immediately after excision under a $\mathrm{N}_{2}$-blanket the soft tissues were frozen in liquid nitrogen. Before isolation of the organs, about $1 \mathrm{ml}$ of hemolymph per mussel was obtained from the sinus of the posterior adductor muscle by a syringe inserted through a notch in the shell adjacent to the muscle. The hemolymph was centrifuged to remove the cells. The plasma was deproteinized by adding $0.8 \mathrm{ml}$ of $70 \%$ perchloric acid per $10 \mathrm{ml}$. The excised organs were homogenized in a Sorvall omnimixer in $2 \mathrm{vol}$ of ice-cold $6 \%$ perchloric acid $(4 \mathrm{vol}$ in case of all muscle tissues). Proteins were removed by centrifugation at $27.000 \mathrm{~g}$ for $15 \mathrm{~min}$

\section{Analysis of free amino acids}

To the deproteinized homogenates of the organs or the hemolymph a known volume of $5 \mathrm{M} \mathrm{K}_{2} \mathrm{CO}_{3}$ was added to obtain a $\mathrm{pH}$ of about 2 . After standing for $1 \mathrm{hr}$ at $0^{\circ} \mathrm{C}$, the precipitated $\mathrm{KClO}_{4}$ was removed by centrifugation. The free amino acids were determined in the supernatant on a LKB-3201 amino acid analyser (Kluytmans et al., 1977). Before analysis the hemolymph was concentrated about 3 times by lyophilization and redissolving into a smaller volume. The following free amino acids were determined: aspartate, asparagine, glutamate, glutamine, serine, threonine, proline, glycine, alanine, and further taurine and hypotaurine.

\section{Determination of succinate}

The deproteinized homogenates were neutralized by addition of $5 \mathrm{M} \mathrm{K}_{2} \mathrm{CO}_{3}$, left for $1 \mathrm{hr}$ at $0^{\circ} \mathrm{C}$ and centrifuged to remove precipitated $\mathrm{KClO}_{4}$. In the organs succinate was determined spectrophotometrically, as described by Kluytmans et al. (1975). Succinate in the hemolymph was concentrated before assay by extracting $1.0 \mathrm{ml}$ of acidified hemolymph with $3 \times 5 \mathrm{ml}$ ethylacetate. The combined ethylacetate fractions were evaporated to dryness. The residue was dissolved in bidistilled water and the $\mathrm{pH}$ adjusted to $8-9$ before spectrophotometric determination of succinate.

In the total animal succinate was determined by isotachophoresis. $1.0 \mathrm{ml}$ of the neutralized homogenate was passed through a Dowex $1 \mathrm{X} 2$ anion exchange column $\left(\mathrm{OH}^{-}\right.$form, $1.5 \mathrm{ml}$ resin).

The column was eluted with $3 \mathrm{ml}$ bidistilled water. This eluant was discarded. Succinate was eluted from the column by $4.5 \mathrm{ml} 4 \mathrm{M}$ formic acid. The eluant was lyophilized, the residue dissolved in $200 \mu \mathrm{l}$ bidistilled water. 5 to $10 \mu \mathrm{l}$ was injected into a LKB-2107 Tachophor equipped with a $63 \mathrm{~cm}$ capillary. Leading electrolyte was $0.01 \mathrm{M}$ $\mathrm{HCl}$, adjusted to $\mathrm{pH} 3.95$ with $\beta$-alanine, terminating electrolyte $0.01 \mathrm{M}$ caproic acid $\mathrm{pH} 4.00$. The current was set on $170 \mu \mathrm{A}$ for $15 \mathrm{~min}$, afterwards on $70 \mu \mathrm{A}$.

\section{Analysis of volatile fatty acids}

The volatile fatty acids were extracted from the deproteinized homogenate by diethylether. $10 \mathrm{ml}$ homogenate to which an internal standard of $0.1 \mathrm{M}$ valeric acid had been added before the homogenization procedure, was extracted with $3 \times 50 \mathrm{ml}$ freshly distilled diethylether. The combined ether layers were made alkaline with $0.16 \mathrm{M} \mathrm{NaOH}$ dissolved in methanol and evaporated to dryness. The residue

\section{SUCCINATE}
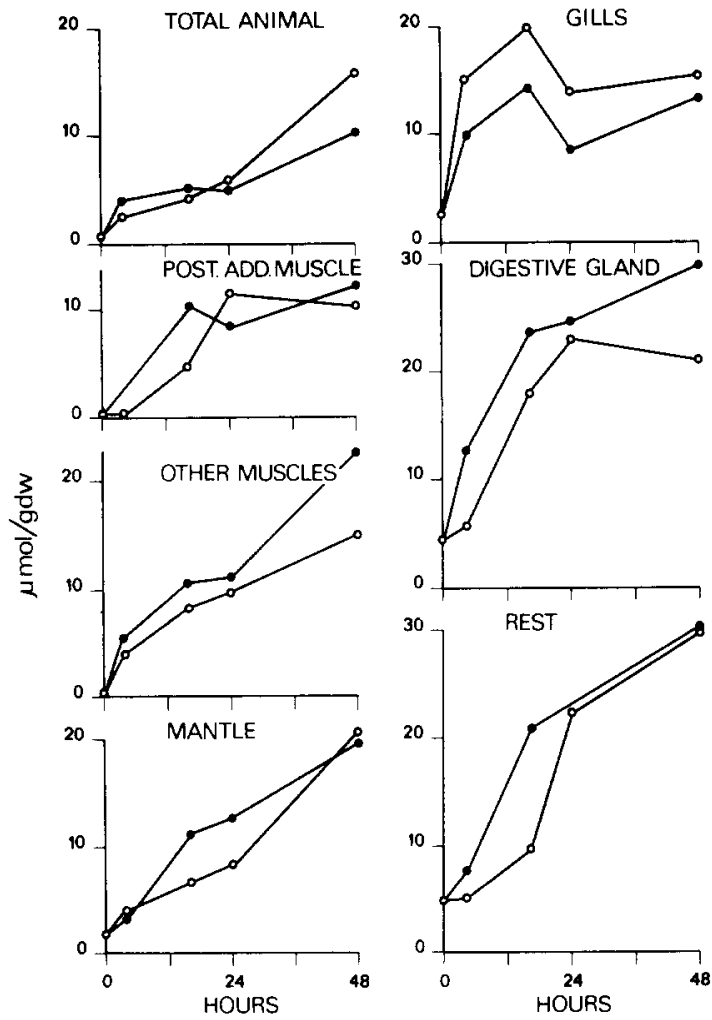

Fig. 1. Accumulation of succinate in Mytilus edulis during exposure to air $\left(\mathrm{O}_{-} \mathrm{O}\right)$ or incubation in oxygen-free seawater (- - $)$ in the total animal and different organs. Concentrations are expressed as $\mu \mathrm{mol} / \mathrm{g}$ dry weight and represent the mean of a pooled group of 30 animals.

\section{ACETATE}
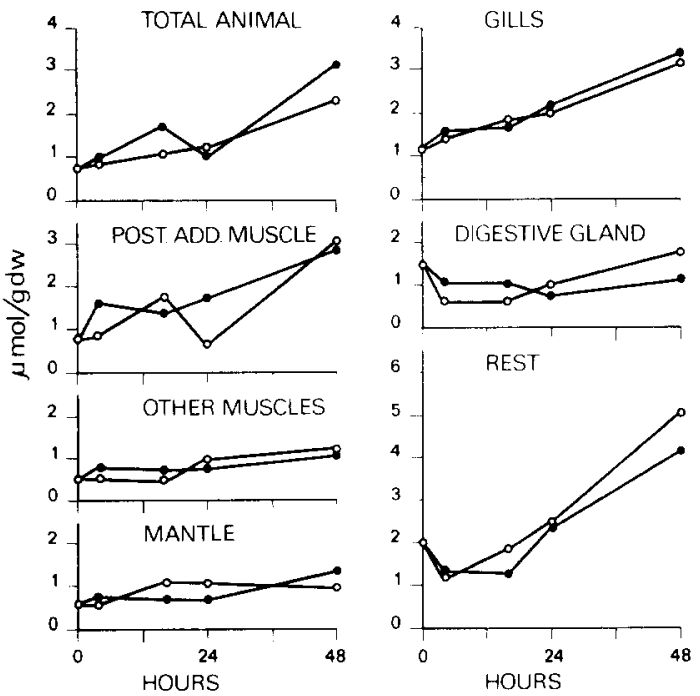

Fig. 2. Acetate accumulation in Mytilus edulis during exposure to air $(0-\mathrm{O})$ or incubation in oxygen-free seawater (-) in the total animal and different organs. Concentrations are expressed as $\mu \mathrm{mol} / \mathrm{g}$ dry weight and represent the mean of a pooled group of 30 animals. 
was dissolved in $1 \mathrm{ml} \quad 25 \% \quad \mathrm{H}_{3} \mathrm{PO}_{4}$ before gaschromatographic analysis of the volatile fatty acids according to the method of Kluytmans et al. (1975).

The excretion of volatile fatty acids in the incubation water was determined by taking aliquots of $250 \mathrm{ml}$, that were lyophilized after addition of $1.0 \mathrm{ml}$ of $1 \mathrm{M} \mathrm{HaOH}$ The lyophilisate was redissolved in $10 \mathrm{ml}$ bidistilled water, acidified and the fatty acids extracted with diethylether as described above. A blank determination was performed in every series of determinations by extracting $10 \mathrm{ml} 6 \%$ perchloric acid with $3 \times 50 \mathrm{ml}$ diethylether. This solvent contained sometimes relatively high amounts of a compound (possibly peroxide) that enlarged the acetate peak in the gas-chromatogram.

\section{RESULTS}

Accumulation of succinate and volatile fatty acids

The time-dependent accumulation of succinate, acetate and propionate is shown for the total animal and the different investigated organs in Figs 1,2 and 3 , respectively. In each figure a comparison is made between animals exposed to air and animals incubated in oxygen-free seawater. Up to $48 \mathrm{hr}$ of anaero- biosis succinate is the main end product of glycogen breakdown in the animals as a whole as well as in the different organs. Succinate seems to increase linearly with time in the total animal exposed to air and in the mantle (Fig. 1). Especially in the adductor muscle, gills and digestive gland the rate of succinate accumulation decreases after 16 and $24 \mathrm{hr}$. In the hemolymph the succinate concentration is very low $(<0.1 \mu \mathrm{mol} / \mathrm{ml})$ and increases only $2-3$ times during $48 \mathrm{hr}$ (Fig. 4).

Acetate is not an important end product in Mytilus. In the total animal acetate rises from 0.7 to $2.4 \mu \mathrm{mol} / \mathrm{g}$ dry weight during $48 \mathrm{hr}$ of exposure, whereas succinate accumulates to about $16 \mu \mathrm{mol} / \mathrm{g}$ dry weight. In the organs and in the hemolymph the same slow increase is observed for acetate (Figs 2 and 4). Besides accumulation in the tissues excretion of acetate is observed (Table 1) for the animals incubated in oxygen-free seawater. After $48 \mathrm{hr}$ of incubation nearly the same quantity of acetate as found in the tissues, is detected in the incubation water: about $2 \mu \mathrm{mol} / \mathrm{g}$ dry weight. Propionate is only detectable after $16 \mathrm{hr}$ of anoxia and accumulates much more rapidly than
A
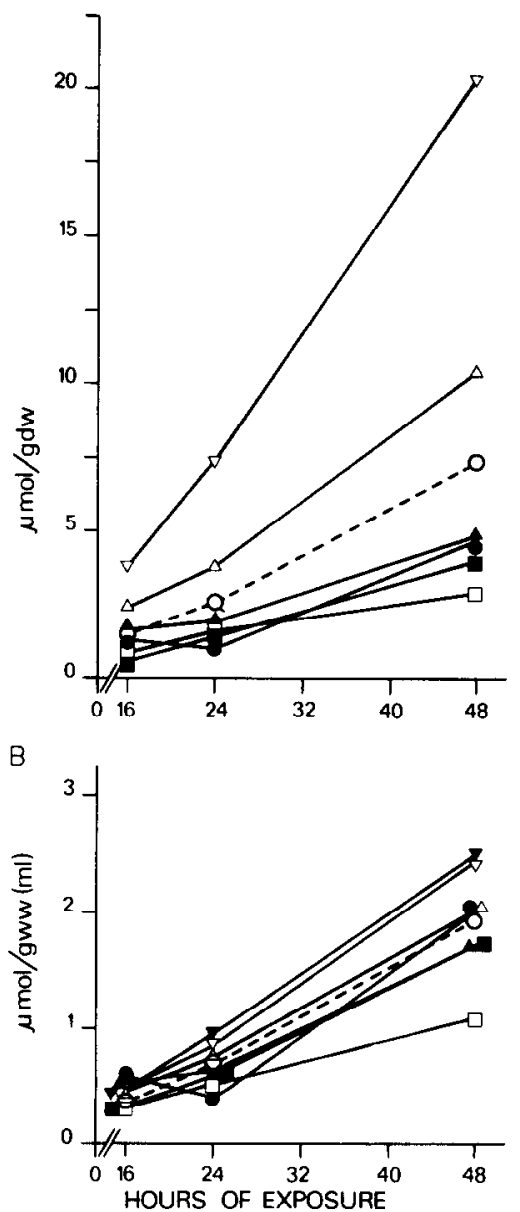

PROPIONATE
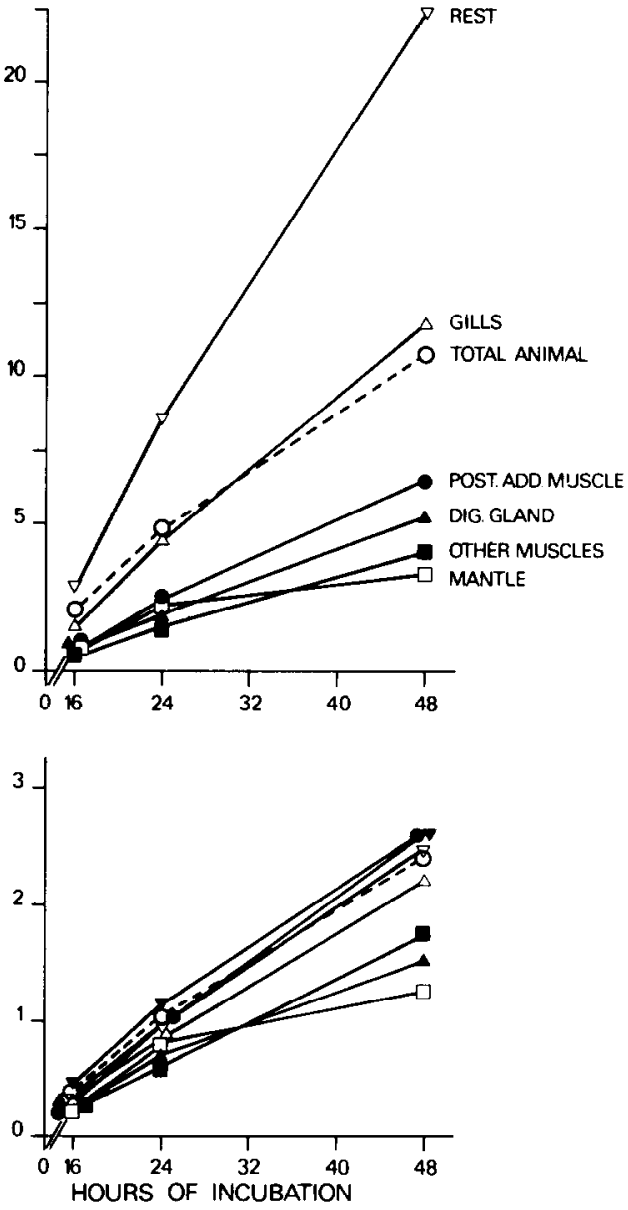

Fig. 3. Propionate accumulation in Mytilus edulis during exposure to air (left) and incubation in oxygenfree seawater (right). A. Concentrations expressed as $\mu \mathrm{mol} / \mathrm{g}$ dry weight. B. Concentrations expressed as $\mu \mathrm{mol} / \mathrm{g}$ wet weight, or $\mathrm{ml}$ hemolymph. All values are the mean of a pooled group of 30 animals. -0 total animal, $-\longrightarrow$ posterior adductor muscle, $\square-\square$ mantle, $\square$ other muscles, $\triangle \triangle \Delta$ gills, $\Delta-\boldsymbol{\Delta}$ digestive gland, $\nabla-\nabla$ rest, $\nabla-\nabla$ hemolymph. 
HEMOLYMPH

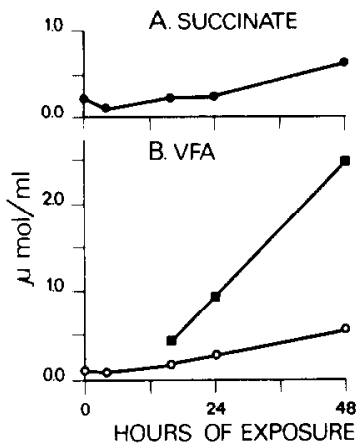

Table 1. Excretion of acetate and propionate by Mytilus edulis $\mathbf{L}$. after different periods of incubation in oxygen-free seawater, expressed as $\mu \mathrm{mol} / \mathrm{g}$ dry weight

\begin{tabular}{ccc}
\hline Time of anoxia (hr) & Acetate & Propionate \\
\hline 0 & N.D.* & N.D. \\
4 & 0.2 & N.D. \\
16 & 0.5 & 1.4 \\
24 & 1.4 & 7.0 \\
48 & 2.1 & 8.6 \\
\hline
\end{tabular}

* $=$ not detectable.

Alanine seems to accumulate in the adductor muscle (incubated group), mantle and digestive gland. Glutamate rises in the adductor muscle (incubated group), the mantle (exposed group) and digestive gland, whereas aspartate decreases in the total animal, the adductor muscle, the gills and the mantle (incubated group).

The other determined amino acids (serine, threonine, asparagine, proline and glycine, as well as taurine and hypotaurine) do not show clear variations during anaerobiosis in the different organs or the total animal.

On the contrary, in the hemolymph more changes can be found. Whereas aspartate and glutamate remain fairly constant (not shown), a decrease can be observed in the concentration of alanine, threonine, serine, asparagine and proline after 24 and $48 \mathrm{hr}$ (Fig. 5).

\section{DISCUSSION}

The animal as a whole was included in our invest $\mathrm{i}$ gation on organ specificity in order to check possible losses of intermediates in the different organs during the isolation procedure which lasted about $2-3 \mathrm{~min}$ for the organs, but only a few seconds for the total animal. The quantities of intermediates found by taking the sum of the organs appeared to be about the same as the quantity found in the animal as a whole.

From the determined free amino acids only alanine, glutamate and aspartate levels show some changes in the tissues due to anaerobic metabolism (Table 2).

Table 2. Concentrations of alanine, glutamate and aspartate after different periods of exposure to air or incubation in oxygen-free sea-water in some organs of Mytilus edulis and in the animal as a whole (concentrations are expressed as $\mu \mathrm{mol} / \mathrm{g}$ dry weight)

\begin{tabular}{|c|c|c|c|c|c|c|c|c|c|c|}
\hline & \multirow{2}{*}{$\begin{array}{l}\text { Time of } \mathrm{O}_{2} \text {-deprivation } \\
\text { (hr) }\end{array}$} & \multicolumn{3}{|c|}{ Alanine } & \multicolumn{3}{|c|}{ Glutamate } & \multicolumn{3}{|c|}{ Aspartate } \\
\hline & & 0 & 24 & 48 & 0 & 24 & 48 & 0 & 24 & 48 \\
\hline \multirow{2}{*}{$\begin{array}{l}\text { Postcrior } \\
\text { adductor } \\
\text { muscle }\end{array}$} & Exposed & 23 & 31 & 25 & 27 & 30 & 28 & 24 & 19 & 19 \\
\hline & Incubated & 23 & 41 & 52 & 27 & 28 & 38 & 24 & 12 & 16 \\
\hline \multirow{2}{*}{$\begin{array}{l}\text { Other } \\
\text { muscles }\end{array}$} & Exposed & 27 & 30 & 39 & 26 & 31 & 33 & 17 & 16 & 17 \\
\hline & Incubated & 27 & 32 & 32 & 26 & 28 & 29 & 17 & 15 & 15 \\
\hline \multirow[t]{2}{*}{ Mantle } & Exposed & 58 & 70 & 74 & 41 & 61 & 62 & 25 & 23 & 21 \\
\hline & Incubated & 58 & 68 & 65 & 41 & 54 & 42 & 25 & 21 & 19 \\
\hline \multirow[t]{2}{*}{ Gills } & Exposed & 23 & 18 & 22 & 25 & 18 & 22 & 36 & 14 & 20 \\
\hline & Incubated & 23 & 18 & 25 & 25 & 18 & 25 & 36 & 19 & 24 \\
\hline \multirow{2}{*}{$\begin{array}{l}\text { Digestive } \\
\text { gland }\end{array}$} & Exposed & 50 & 56 & 65 & 40 & 48 & 54 & 20 & 21 & 20 \\
\hline & Incubated & 50 & 64 & 66 & 40 & 50 & 56 & 20 & 23 & 23 \\
\hline \multirow[t]{2}{*}{ Rest } & Exposed & 97 & 80 & 74 & 85 & 69 & 70 & 40 & 30 & 33 \\
\hline & Incubated & 97 & 81 & 63 & 85 & 64 & 51 & 40 & 29 & 17 \\
\hline \multirow{2}{*}{$\begin{array}{l}\text { Total } \\
\text { animal }\end{array}$} & Exposed & 50 & 45 & 43 & 36 & 31 & 27 & 28 & 18 & 16 \\
\hline & Incubated & 50 & 57 & 52 & 36 & 34 & 33 & 28 & 19 & 19 \\
\hline
\end{tabular}


HEMOLYMPH
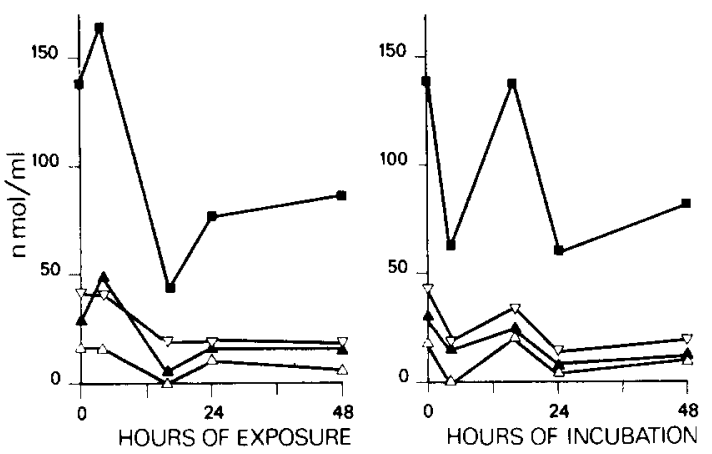

Fig. 5. Changes in the concentrations of free amino acids in the hemolymph of Mytilus edulis during exposure to air (left) or incubation in oxygen-free seawater (right). alanine, $\nabla-\nabla$ threonine, $\Delta-\Delta$ aspartate, $\Delta-\Delta$ proline. Concentrations are expressed as $\mathrm{nmol} / \mathrm{ml}$ and are based on a pooled group of 30 animals.

The mantle and the muscles, excluding the posterior adductor muscle, represented about $55 \%$ of the dry weight of the total mussel. In these organs as well as in the digestive gland and the rest the highest accumulation of succinate is observed, almost linear in the mantle, the other muscles and the rest, like in the total animal. In the remaining organs, especially in the gills the succinate accumulation seems to level off after $16 \mathrm{hr}$ of exposure to air or incubation without oxygen (Fig. 1). This has been observed earlier by Kluytmans et al. (1977) and may be an indication that at this stage propionate is formed from succinate.

Comparison of the two experimental conditions, exposure to air or incubation in oxygen-free seawater does not reveal marked differences. The concentration of succinate in the hemolymph is very low compared to the tissue levels (Fig. 4). Since moreover no excretion of succinate has been observed (Kluytmans et al., 1978), it can be argued that succinate accumulates only in the tissues and is not transported. Nevertheless, we cannot exclude that succinate present in the hemolymph could be taken up rapidly by some organ(s) and converted into propionate, which would keep the succinate level in the hemolymph low.

\section{Volatile fatty acids}

The accumulation pattern of acetate in the exposed and in the incubated groups is almost identical. The mussels incubated in oxygen-free seawater, though excreted acetate and well nearly as much as was found in the tissues. For the total animal the tissue concentration after $48 \mathrm{hr}$ of anoxia was about $3 \mu \mathrm{mol} / \mathrm{g}$ dry weight (Fig. 2) whereas $2.1 \mu \mathrm{mol} / \mathrm{g}$ dry weight was excreted in the incubation water (Table 1). The same is observed for propionate. The tissue concentration after $48 \mathrm{hr}$ was 7.4 and $10.8 \mu \mathrm{mol} / \mathrm{g}$ dry weight, respectively, in the exposed and in the incubated group (Fig. 3). In addition, $8.6 \mu \mathrm{mol} / \mathrm{g}$ dry weight was excreted by the incubated mussels.

The only marked difference between the exposed and the incubated group seems to be an extra production of volatile fatty acids, that are excreted when this possibility is offered to the animals by surrounding them by seawater. The extra production could be due to a higher activity of the mussels. When exposed to air the animals keep their valves tightly closed, but gape in oxygen-free seawater. In the latter condition normally aerobic activities as filtration may continue. On the other hand some oxygen consumption in air as observed by Widdows et al. (1979) could influence the extent to which anaerobic end products are formed.

From the results shown in Figs $3 \mathrm{~A}$ and $\mathrm{B}$ it is difficult to draw conclusions about organ specificity in propionate production. When the concentrations are expressed as $\mu \mathrm{mol} / \mathrm{g}$ dry weight, the gills and the rest seem to produce more propionate. These tissues, however, have a higher water content than the other organs. In the gills relatively large hemolymph vessels are present, while in the rest the enclosed seawater is comprised as well as hemolymph leaking from the tissues during the excision procedure.

In Fig. 3B the concentrations are expressed as $\mu \mathrm{mol} / \mathrm{g}$ wet weight. In this case the propionate accumulation is more identical in all investigated organs. After $16 \mathrm{hr}$ of anoxia when the production only has started a few hours, propionate is detected in the incubation water. This could indicate a very easy transport of this compound. Experiments with injection of propionate also show that propionate can find its way very easily from one place in the mussel body to another (Zurburg, in preparation). It might be possible that propionate is produced in some organ(s) and is transported or diffuses from the place of production to every part in the body or is excreted. The concentration of propionate in the hemolymph expressed as $\mu \mathrm{mol} / \mathrm{ml}$ falls in the range of the tissue concentrations expressed as $\mu \mathrm{mol} / \mathrm{g}$ wet weight. (Fig. $3 \mathrm{~B})$. In vitro experiments are in progress to obtain more evidence whether propionate production is a feature common to all organs or is mainly localized in one or a few organs.

\section{Free amino acids}

The present experiment was carried out in summer when in the total animal hardly any changes in the levels of free amino acids (expecially alanine) due to anaerobiosis are observed in contrast to winter and spring time (Kluytmans et al., 1980). The decrease in aspartate levels in the total animal, the adductor muscle and the gills may be caused by utilization of this amino acid as a precursor for succinate. Aspartate can be transaminated to oxaloacetate that can be further converted into succinate. The transamination of aspartate can result in formation of alanine or glutamate. This has also been suggested by Collicut $\&$ Hochachka (1977) for the heart of Crassostrea virginica.

In the posterior adductor muscle a marked difference is observed between the exposed and incubated groups. Only in the last group the alanine and to some extent glutamate levels increase while the aspartate level decreases.

It has been suggested by Wijsman (1975) that the drop in $\mathrm{pH}$ in the body fluids of $M$. edulis is smaller in animals incubated in seawater than in exposed animals. Pyruvate kinase will be less inhibited by $\mathrm{H}^{+}$but the observed succinate and propionate concentrations are about the same in the posterior adductor muscle 
after $48 \mathrm{hr}$ of exposure to air or incubation in oxygenfree seawater. When pyruvate kinase is still active, succinate could be formed from aspartate, whilst pyruvate formed by pyruvate kinase is trans-aminated to alanine. In the exposed group succinate will be formed mainly via the phosphoenolpyruvate carboxykinase route, in the incubated group aspartate will be used as a precursor for succinate. Recently we could not confirm the results obtained by Wijsman. No clear difference in $\mathrm{pH}$ was shown between exposed or incubated animals (Zurburg \& Ebberink, unpublished data). Possibly factors other than $\mathrm{pH}$, regulating the phosphoenolpyruvate branchpoint, will explain the different pathways for the production of succinate.

It is not clear if the changes in the concentrations of amino acids in the rest are of physiological signifcance. The composition of this fraction may be inconsistent, because the more important and larger organs were isolated separately.

Decreases in the levels of free amino acids in the hemolymph during anoxia as found in the present experiment, have also been observed by Hanson \& Dietz (1976) in the freshwater mussel Ligumia subrostrata. Under anoxia blood $\mathrm{Ca}^{2+}$ increases, probably by mobilization from the shell by metabolic acids (succinate, volatile fatty acids). As a consequence the blood osmolarity increases and to maintain the intracellular fluid isosmotic with the blood, the cells could take up free amino acids. The decrease in the levels in the hemolymph is, however, small $(<0.5 \mu \mathrm{mol} / \mathrm{ml})$ compared to the increases in e.g. alanine in the tissues, so at present no conclusions can be drawn whether the proposed uptake occurs. Moreover, it is not possible to discriminate accumulation due to anoxia or uptake from the hemolymph.

Acknowledgements-The authors wish to thank Professor Dr D. I. Zandee for his interest in the investigations and $\mathrm{Mr} \mathrm{H} . \mathrm{J}$. L. Ravestein for his skilful assistance in the determination of the free amino acids.

\section{REFERENCES}

Collicut J. M. \& Hochachka P. W. (1977) The anaerobic oyster heart: Coupling of glucose and aspartate fermentation. J. comp. Physiol. 115, 147-157.

Hanson J. A. \& Dietz T. H. (1976) The role of free amino acids in cellular osmoregulation in the freshwater bivalve Ligumia subrostrata (Say). Can. J. Zool 54, 1927-1931.

Kluytmans J. H., Bont A. M. T. DE, Janus J. \& Wissman T. C. M. (1977) Time dependent changes and tissue specificities in the accumulation of anaerobic fermentation products in the sea mussel Mytilus edulis L. Comp. Biochem. Physiol. 58B, 81-87.

Kluytmans J. H., Graft M. van, Janus J. \& Pieters H (1978) Production and excretion of volatile fatty acids in the sea mussel Mytilus edulis L. J. comp. Physiol. 123, 163-167.

Kluytmans J. H., Veenhof P. R. \& ZwaAn A. de (1975) Anaerobic production of volatile fatty acids in the sea mussel Mytilus edulis L. J. comp. Physiol. 104, 71-78.

Kluytmans J. H., Zandee D. l., Zurburg W. \& Pieters H. (1980) The influence of seasonal changes on energy metabolism in Mytilus edulis L. III. Anaerobic energy metabolism. Comp. Biochem. Physiol. 67B, 307-315.

Livingstone D. R. \& BAyNe B. L. (1977) Responses of Mytilus edulis $\mathrm{L}$. to low oxygen tension: anaerobic metabolism of the posterior adductor muscle and mantle tissues. J. comp. Physiol. 114, 143-155.

Widdows J., Bayne B. L., Livingstone D. R., Newell R. I. E. \& Donkin P. (1979) Physiological and biochemical responses of bivalve molluses to exposure to air. Comp. Biochem. Physiol. 62A, 301-308.

Wissman T. C. M. (1975) pH fluctuations in Mytilus edulis $\mathrm{L}$. in relation to shell movements under aerobic and anaerobic conditions. Proceedings of the $9 t h$ European Marine Biology. Symposium (Edited by BARNES H.) pp. 139-149. Aberdeen University press, Aberdeen.

Zurburg W., Kluytmans J. H., Pieters H. \& Zandee D. I. (1979) The influence of seasonal changes on energy metabolism in Mytilus edulis L. II. Organ specificity. In Cyclic Phenomena in Marine Plants and Animals (Edited by NaYlor E. \& Hartnoll R. G.) pp. 293-300. Pergamon Press, Oxford.

ZWAAN A. DE (1977) Anaerobic energy metabolism in bivalve molluscs. Oceanogr. mar. Biol. Ann. Rev. 15, 103-187. 